\title{
Augmentative Effects of Working Memory Training on Clinical Symptoms and Neuropsychology in Medicated Children and Adolescents with Attention-Deficit Hyperactivity Disorder
}

\author{
Hye Sun Kim¹, Eun Kyung Lee', In Hwa Hong', Jung Sook $\mathrm{An}^{2}$, and Hanik K. Yoo \\ ${ }^{1}$ Seoul Brain Research Institute, Seoul, Korea \\ ${ }^{2}$ Seoul Regional Military Manpower Administration, Seoul, Korea
}

\author{
약물치료 중인 주의력결핍 과잉행동장애 아동 청소년에서 작업기억력 훈련이 임상증상과 \\ 신경심리소견에 미치는 부가적 효과 \\ 김혜선 ${ }^{1}$, 이은경 ${ }^{1}$, 홍인화 $^{1}$, 안정숙 $^{2}$, 유한익 ${ }^{1}$ \\ 서울뇌과학연구소, ${ }^{1}$ 서울지방병무청 ${ }^{2}$
}

\begin{abstract}
Objectives: Executive dysfunction including working memory deficit has been suggested to be one of the major neuropsychological etiologies of attention-deficit hyperactivity disorder (ADHD). The purpose of this study was to investigate the augmentative effects of Cogmed working memory training on the symptoms and neurocognitive functions in medicated children and adolescents with ADHD.

Methods: Twenty-five children with ADHD, aged 7 to 19 years, taking ADHD medication participated in this study. The participants were trained for 5 weeks with a commercially available and computerized working memory program $\left(\mathrm{Cogmed}^{\circledR}\right)$ without any changes to their medication. The Korean version of the ADHD Rating Scale, Clinical Global Impression Scale, and Comprehensive Attention Test were administered before training and 4 weeks and 7 months after training, respectively.

Results: After completing the training, the clinical symptoms and function, rated by the parents and clinician, were improved. In addition, the level of commission errors was significantly reduced in the selective attention (visual/auditory) task, sustained attention to response task, and flanker task. The untrained visuospatial short-term memory and working memory were also improved. These effects were still observed 7 months after the training.

Conclusion: Cogmed working memory training can be a promising training option for the additional improvement of the symptoms and deficits in working memory and response inhibition in medicated children with ADHD.
\end{abstract}

Key Words: Working memory training; Cogmed; Attention-deficit hyperactivity disorder; Neuropsychology.

Received: October 20, 2016 / Revision: January 20, 2017 / Accepted: February 18, 2017

Address for correspondence: Hanik K. Yoo, Seoul Brain Research Institute, 10 Gangbyeonyeok-ro 4-gil, Gwangjin-gu, Seoul 05116, Korea Tel: +82-2-452-2150, Fax: +82-2-6280-2163, E-mail: hanikyoo@gmail.com

\section{서 론}

주의력결핍 과잉행동장애(attention-deficit hyperactivity disorder, $\mathrm{ADHD}$ )는 부주의와 과잉행동, 충동성이 주된 증상 인 정신과 질환으로서 ${ }^{1)}$ 행동문제와 학습부진을 일으키며, 결 국 학업적, 사회적, 정서적 기능의 손상을 초래한다. $\mathrm{ADHD}$ 는

This is an Open Access article distributed under the terms of the Creative Commons Attribution Non-Commercial License (http://creativecommons.org/licenses/by-nc/4.0) which permits unrestricted non-commercial use, distribution, and reproduction in any medium, provided the original work is properly cited.
주로 학령기 이전에 발병하며, 유병률은 학령기 아동에게서 약 $5 \%$ 에 달하고 여아보다는 남아에게서 3 배가량 흔하다.

$\mathrm{ADHD}$ 아동은 무관한 자극에 반응하는 것을 억제하고 유 관한 자극에 반응하는 선택주의력과 장기간 집중을 유지하 는 지속주의력이 부족하며 주의력의 전체적인 수용능력이 부 족해서 보다 높은 수준의 주의집중이 요구되는 과제에서 낮은 수행을 보인다. ${ }^{3)}$ 이외에도 행동억제의 결함, 정보처리속도, 작 업기억력, 실행기능, 반응 변이도와 같은 광범위한 신경심리기 능에서의 이상소견이 있는 것으로 알려져 있다. ${ }^{24)}$ 선행연구에 
따르면 $\mathrm{ADHD}$ 는 전두엽 부위에서 중개되는 실행기능의 결함 을 보이는데, 여기에는 정보처리속도, 작업기억력, 인지적 융통 성, 반응 억제, 논리적 추론능력, 계획 및 조직화 능력, 운동통 제, 선택주의력, 언어적 유창성 등의 이상이 포함된다. ${ }^{5-10)}$

$\mathrm{ADHD}$ 의 핵심적인 인지 결손 중 하나는 작업기억력의 결함 이다. ${ }^{11,12}$ 작업기억력은 수초 동안 정보를 기억하고 사고과정 중에 이를 사용하고 조작하는 능력을 일컫는데, ${ }^{13)}$ 대부분의 $\mathrm{ADHD}$ 아동은 작업기억력 검사에서 정상 아동보다 낮은 수행 을 보인다. ${ }^{14,15)}$ 작업기억력의 부족으로 인해 $\mathrm{ADHD}$ 아동은 자 신이 수행해야 할 일을 기억하지 못하고 다른 자극을 억제하 지 못해 쉽게 산만해진다. ${ }^{16}$ 또한 작업기억력의 결함은 $\mathrm{ADHD}$ 의 주요 증상인 부주의, 과잉행동, 충동성의 발현과 깊은 연 관성이 있는 것으로 알려져 있다. ${ }^{17-19)}$

$\mathrm{ADHD}$ 아동의 치료를 위해 가장 널리 사용되는 방법은 약물 치료이다. 메칠페니데이트(methylphenidate)가 가장 많이 사용되 는 약물이며, $\mathrm{ADHD}$ 아동의 최소 $70 \%$ 이상에서 주의력 향상, 충동성 및 과잉행동의 감소, 학습능력의 개선을 보인다. ${ }^{20-22)}$ 또한 약물치료 후 지속주의력과 경계력, 반응 일관성, 간섭 자 극에 대한 차단 능력, 작업기억력이 향상되고, 충동적인 반응 이 감소하는 등 다양한 신경인지기능의 호전이 보고되고 있 다. ${ }^{23-25)}$ 하지만 $\mathrm{ADHD}$ 아동의 20 30\%는 약물치료의 도움을 크게 받지 못하며, ${ }^{26,27)}$ 약물치료가 중단되면 이전 상태로 돌아 가기도 한다. ${ }^{28)}$ 실제 임상에서는 아동이나 보호자가 약물치료 자체를 거부하거나 불면증, 식욕부진, 성장지체 등의 부작용 으로 인해 약물치료를 꺼리는 경우도 종종 있다. ${ }^{29)}$ 또한 약물 치료 단독, 행동치료 단독, 약물과 행동치료의 병합치료, 지역 사회치료의 효과를 장기적으로 비교한 Multimodal Treatment Study of Children with ADHD 결과에 따르면, 치료 후 14개월 이 경과한 시점에는 약물치료와 병합치료 그룹에서 부주의, 과잉행동-충동성, 적대적/공격적 행동 및 내향화 증상, 읽기 성취도 점수 등에서 개선 효과가 높았으나, 3년과 8년 시점에는 모든 영역에서 약물치료 및 병합치료가 가졌던 효과와 이득 이 사라졌다. ${ }^{30-32)}$ 이는 비약물치료만으로는 $\mathrm{ADHD}$ 의 핵심증 상을 개선하기 어렵다는 사실과 함께 약물치료의 장기적 효과 에 대한 증거가 확실하지 않음을 시사한다. ${ }^{33-35)}$

현재까지 약물치료와 병행하여 $\mathrm{ADHD}$ 의 증상을 완화시킬 수 있는 다양한 비약물적 중재기법에 대한 연구가 지속되고 있는데 ${ }^{36)}$ 비약물적 중재기법에는 행동치료와 인지행동치료, 뉴로피드백 훈련 등이 있다. 행동치료는 문제행동의 감소, 또 래관계 개선에는 효과가 있지만, 긍정적이고 사회적인 행동 변 화가 내적 동기보다는 외적 보상에 의존하기 때문에 보상이 철 회될 경우 변화가 일상생활에 지속되지 못한다는 제한점이 있 다. ${ }^{37)}$ 인지행동치료도 문제행동 감소와 사회성 증진에 효과가
있었으나 약물치료를 병행하지 않고서는 인지행동치료 단독 으로는 효과가 부족하였고, 일부 연구에서는 심한 행동문제를 가진 ADHD 아동에게는 효과가 없었다. ${ }^{37-40)}$ 뉴로피드백 훈련 또한 대안으로 제시되고 있으나, 여러 연구 결과 현재까지는 $\mathrm{ADHD}$ 아동에게 효과적이라는 증거가 부족한 상태이다. ${ }^{41-43)}$

그동안 작업기억력의 결함이 $\mathrm{ADHD}$ 의 증상 형성에 핵심적 인 역할을 한다는 사실을 근거로 훈련을 통해 작업기억력을 개선하고자 하는 시도가 있어 왔다. 오랫동안 작업기억력의 용 량은 고정된 특성으로 간주되었으나, 최근의 신경과학적 연구 결과에서는 뇌가 가소성을 지녔고 작업기억력도 훈련을 통해 향상될 수 있음이 입증되고 있다. ${ }^{44,45}$ 그중 하나로 코그메드 작 업기억력 훈련(Cogmed Working Memory Training, CWMT) 이 개발되었다. CWMT는 컴퓨터를 이용한 전산화된 프로그 램으로써 훈련된 코치에 의해 5 주간 실시된다. CWMT를 통 해 작업기억력을 집중적이고 최적화된 방식으로 훈련시킴으 로써, 주의력은 물론 다른 인지기능까지 개선시키는 것으로 알려졌다. ${ }^{46}$ Klingberg 등 ${ }^{47)}$ 은 $\mathrm{ADHD}$ 로 진단받았으나 약물치 료를 받지 않은 7 12세 사이 아동 53명에게 CWMT를 실시하 여 무작위 위약 대조 연구를 진행하였는데, 그 결과 훈련받은 작업기억력뿐만 아니라 훈련받지 않은 작업기억력, 반응 억제 력, 추론능력이 향상되었고, 부모평정 척도에서 $\mathrm{ADHD}$ 의 증 상이 유의하게 감소되었으며, 이 효과는 훈련 후 3개월까지 지 속되었다. 이후 CWMT를 사용한 여러 연구에서 비언어적/언 어적 작업기억력, 훈련받지 않은 언어적/비언어적 단기기억력, 정신운동속도, 수학과 읽기능력, 지시이행능력의 향상과 과제 외 행동(off-task behavior)의 감소가 보고되었고 ${ }^{48-52)}$ 이들 훈 련 효과는 훈련 직후 또는 지연된 효과(delayed effect)로서 나 타나며, 최장 8개월 내지 1년까지 지속되었다. ${ }^{52,53)} \mathrm{CWMT}$ 를 통 해 직접적으로 훈련하지 않은 인기기능까지 호전되었는데, 이 는 CWMT가 전두-두정엽과 기저핵의 뇌 활성도 변화와 도파 민 수용체의 밀집도 변화를 일으키고, 결국 신경망에 변화를 일으켜 직접적으로 훈련하지 않은 인지기능에도 훈련 효과가 전이되는 것으로 생각된다. ${ }^{46,54)}$

본 연구에서는 CWMT가 국내 ADHD 아동의 핵심증상과 신경인지기능을 향상시키는지 알아보고자 한다. 특히 $\mathrm{ADHD}$ 는 대부분 약물치료를 받기 때문에, CWMT가 약물로 인해 변 화된 증상과 인지기능에 부가적인 향상을 일으킬 수 있는지 를 확인하고자 대상군에게 약물을 그대로 유지한 상태에서 훈련을 실시하였다. 


\section{방 법}

\section{대상 및 과정}

주의력 문제로 서울 소재 소아청소년정신과 외래에 내원한 아동 및 청소년 중 소아청소년정신과 전문의가 DSM-IV-R에 의해 $\mathrm{ADHD}$ 로 진단한 환자를 대상으로 하였다. 진단은 병력 청취와 정신과적 진찰, 심리검사 결과를 종합하여 내려졌다. 자신 및 보호자의 동의하에 초등학교 1학년에서부터 고등학 교 3학년에 재학 중인 남녀 $\mathrm{ADHD}$ 아동이 본 연구에 참가하였 고, 웩슬러 지능검사로 측정한 지능지수가 70 이하인 아동 55 과 품행장애, 반항장애, 불안장애, 우울장애 등의 공병이 심한 아동은 연구에서 제외시켰다. 총 25 명이 연구에 참가하였고, 연구대상자들은 이미 약물치료를 통해 증상이 부분적으로 호전된 상태였다. 약물복용 후 부작용을 견딜 수 있는 상태에 서 8주간 경과를 관찰하였으며, 여전히 임상가용 한국판 주의 력결핍 과잉행동장애평가 척도를 통해 증상이 남아 있다고 확 인된 아동들을 연구대상자에 포함시켰다. 최근 4주 이상 약물 의 종류와 용량을 변경하지 않은 상태에서 연구가 진행되었 고, 연구기간 동안 약물의 종류와 용량을 변경하지 않았다.

작업기억 훈련은 5 주간 25 회 진행되었으며, 훈련 효과를 측 정하기 위해 훈련 전, 훈련 후 1 개월, 훈련 후 7개월 시점에 평 가하였다.

모든 연구 과정은 연구윤리위원회의 승인(IRB No. 7001355201504-HR-053) 후에 실시되었다.

\section{연구 도구}

코그메드 작업기억력 훈련(Cogmed Working Memory Training, CWMT)

전산화된 프로그램인 CWMT는 총 25회로 구성되고, 5 주간 일주일에 5일을 훈련하게 되며, 각 훈련 세션은 30 45분간 진 행된다. 코그메드 작업기억력 훈련은 소정의 수련을 받아 인증 받은 코치에 의해 개별적으로 실시되었다. 아동과 부모는 코 치와 함께 훈련 일정을 계획하고, 훈련의 진행 상황과 결과를 스스로 확인할 수 있는 기회를 부여받았으며, 코치는 각 아동 의 훈련을 담당하고 결과를 모니터링하며, 동기를 북돋고 지 원하는 역할을 하였다. 코그메드 작업기억력 훈련에 포함된 하 위훈련들은 아동이 각 훈련에서 최대한의 효과를 얻을 수 있 도록 실시간으로 훈련의 난이도가 조절되었다. ${ }^{47)}$

한국판 주의력결핍 과잉행동장애평가 척도(Korean version of ADHD Rating Scale, K-ARS)

ADHD Rating Scale(ARS)은 DuPaul ${ }^{56)}$ 에 의해 개발된 척
도로서, $\mathrm{ADHD}$ 증상의 심각도를 평가하기 위해 고안되었다. 이 척도는 $\mathrm{DSM}-\mathrm{IV}$ 의 $\mathrm{ADHD}$ 진단기준을 반영한 총 18 문항 으로 구성되어 있다. 각각의 문항은 아동의 문제행동 빈도에 따라서 4점 Likert 척도로 평정될 수 있다(0점='전혀 혹은 그 렇지 않다', 1점='때때로 그렇다', 2점='자주 그렇다, 3점='매우 자주 그렇다'). 홀수 문항의 총점은 부주의성을 측정하고, 짝 수 문항의 총점은 과잉행동/충동성을 측정하도록 배열되었다. Korean version of ADHD Rating Scale은 So 등 ${ }^{57}$ 에 의해 한 국어로 번역되어, 신뢰도와 타당도가 유용한 것으로 알려져 있다. 본 연구에서는 임상가용과 부모용이 모두 사용되었다.

전반적 임상 인상 척도(Clinical Global Impression Scale, CGI)

Clinical Global Impression Scale(CGI)은 평가 대상자의 기 능에 대하여 정신병리현상의 유무에 비교적 큰 영향을 받지 않고 전반적인 기능에 대한 평가가 가능한 척도로 알려져 있 다. ${ }^{58)}$ 본 연구에서는 훈련 전, 훈련 후 1 개월, 후련 후 7 개월이 되는 세 시점에서 CGI-Severity(CGI-S: 1=not ill, 2=very mild, 3=mild, 4=moderate, 5=marked, 6=severe, 7=extremely severe) 점수를 평가하였고, 훈련 후 1개월, 훈련 후 7개월이 되는 두 시점에서 CGI-Improvement(CGI-I, 1=very much improved, 2=much improved, 3=minimally improved, 4=no change, $5=$ minimally worse, $6=$ much worse, $7=$ very much worse) 점수를 통하여 표적증상의 호전 여부를 확인하였다. 이 중 CGI-I 1점과 2점을 반응군으로, 3점을 부분반응군으로 분류하였다.

\section{종합주의력검사(Comprehensive Attention Test, CAT)}

Comprehensive Attention Test(CAT)는 주의력에 대한 평 가를 위해 사용되는 전산화된 지속수행검사의 일종으로 주 의집중력 및 충동조절능력을 정량적으로 측정하는 도구이며, 국내에서 개발 및 표준화가 이루어졌다. ${ }^{59)} \mathrm{CAT}$ 는 단순선택주 의력(시각), 단순선택주의력(청각), 억제지속주의력, 간섭선택 주의력, 분할 주의력, 작업기억력의 6가지 소검사로 구성되며, 아동의 연령에 따라 적합한 검사가 시행된다. 각각의 소검사에 서는 누락오류(omission errors), 오경보 오류(commission errors), 반응시간 평균(mean reaction time), 반응시간 표준편차 (standard deviation of reaction time; response time variability) 등의 4 가지 지표가 산출된다.

\section{통계적 분석방법}

통계적 검증은 SPSS for Windows(version 15.0; SPSS Inc., Chicago, IL, USA)를 이용하였다. 훈련의 효과를 살펴보기 위해 훈련 전, 훈련 후 1 개월, 훈련 후 7 개월의 세 평가 시점을 
Table 1. Demographic and clinical characteristics of study subjects $(n=25)$

\begin{tabular}{lc}
\hline & Mean \pm SD or $n(\%)$ \\
\hline Age (years) & $13.1 \pm 3.0$ \\
Sex (male) & $17(68.0)$ \\
IQ & $102.2 \pm 17.6$ \\
ADHD subtype & \\
Combined type & $9(36.0)$ \\
Predominantly inattentive & $16(64.0)$ \\
$\quad$ type & $0(0.0)$ \\
Predominantly hyperactive- & \\
$\quad$ impulsive type & \\
Comorbidities & $6(24.0)$ \\
Depressive disorder & $2(8.0)$ \\
Oppositional-defiant disorder & $1(4.0)$ \\
Conduct disorder & $4(16.0)$ \\
Learning disorder & $2(8.0)$ \\
Anxiety disorder & \\
Medications (mg/day) & \\
MPH dose & $59.79 \pm 25.87(56.0)$ \\
Atomoxetine dose & $46.00 \pm 25.10(20.0)$ \\
MPH+atomoxetine dose & $43.00 \pm 33.10$, \\
& $26.67 \pm 18.94(24.0)$ \\
\hline ADHD: a &
\end{tabular}

ADHD: attention-deficit hyperactivity disorder, MPH: methylphenidateosmotic release, SD: standard deviation
피험자 내 변인으로 하여 Friedman test와 Wilcoxon signed rank test를 실시하였다. 통계적 유의수준은 $\mathrm{p}<0.05$ (양측검정) 로 하였다.

\section{결 과}

\section{인구통계학적, 진단적 특성}

본 연구 대상 아동의 인구통계학적, 진단적 특성은 Table 1 과 같다. 아동은 총 25 명이었으며 남아 17 명, 여아 8 명이었다. 평균 연령은 $13.1 \pm 3.0$ 세였고, 평균 지능지수는 $102.2 \pm 17.6$ 이 었다. $\mathrm{ADHD}$ 의 하위유형은 주의력결핍 우세형 16명(64.0\%), 복합형 9명(36.0\%)이었고, 공존질환은 우울장애 6명(24.0\%), 적대적반항장애 2 명(8.0\%), 품행장애 1명(4.0\%), 학습장애 4명 (16.0\%), 불안장애 2명(8.0\%)이었다. 훈련 중 methylphenidate 를 복용한 경우는 14 명 $(56.0 \%$, 평균용량 $59.8 \mathrm{mg} / \mathrm{day})$, atomoxetine을 복용한 경우는 5명(20.0\%, 평균용량 $46.0 \mathrm{mg} / \mathrm{day})$, 둘 다 복용한 경우는 6명(24.0\%, 평균용량은 methylphenidate 43.0 $\mathrm{mg} /$ day, atomoxetine $26.7 \mathrm{mg} /$ day)이었다.

Table 2. Changes of the ARS from baseline to 1 month and 7 months after training $(n=25)$

\begin{tabular}{|c|c|c|c|c|c|c|}
\hline & Baseline & Month 1 & Month 7 & & & \\
\hline Variables & $\begin{array}{c}\text { Mean } \pm \text { SD } \\
\text { or } \mathrm{n}(\%)\end{array}$ & $\begin{array}{c}\text { Mean } \pm S D \\
\text { or } \mathrm{n}(\%)\end{array}$ & $\begin{array}{c}\text { Mean } \pm \text { SD } \\
\text { or } \mathrm{n}(\%)\end{array}$ & df & $\chi^{2}$ or Z & $\mathrm{p}$ \\
\hline \multicolumn{7}{|l|}{ K-ARS (clinician) } \\
\hline Total score $e^{\ddagger, \S, \|}$ & $15.12 \pm 8.18$ & $10.21 \pm 7.17$ & $7.48 \pm 5.23$ & 2 & 36.87 & $<0.001^{\dagger}$ \\
\hline Inattention score & $12.29 \pm 5.20$ & $8.42 \pm 5.18$ & $6.26 \pm 4.19$ & 2 & 35.32 & $<0.001^{\dagger}$ \\
\hline Hyperactivity-impulsivity score ${ }^{\ddagger \S, \| l}$ & $2.91 \pm 5.14$ & $1.79 \pm 3.88$ & $1.22 \pm 2.59$ & 2 & 15.77 & $<0.001^{\dagger}$ \\
\hline \multicolumn{7}{|l|}{ K-ARS (parent) } \\
\hline Total score $e^{\ddagger, \|}$ & $14.54 \pm 7.28$ & $11.64 \pm 5.84$ & $10.22 \pm 6.40$ & 2 & 8.10 & $0.017^{*}$ \\
\hline Inattention score ${ }^{\ddagger \S, \|}$ & $10.92 \pm 6.24$ & $8.44 \pm 5.13$ & $7.91 \pm 5.29$ & 2 & 7.37 & $0.025^{*}$ \\
\hline Hyperactivity-impulsivity score" & $3.63 \pm 3.17$ & $3.20 \pm 3.43$ & $2.30 \pm 2.69$ & 2 & 7.92 & $0.019 *$ \\
\hline CGI-S $\$, \S, \|$ & $3.67 \pm 0.82$ & $3.04 \pm 0.95$ & $2.52 \pm 1.04$ & 2 & 27.11 & $<0.001^{\dagger}$ \\
\hline \multicolumn{7}{|l|}{ CGIII } \\
\hline Very much improved & - & $0(0.0)$ & $5(20.0)$ & & & \\
\hline Much improved & - & $10(40.0)$ & $10(40.0)$ & & & \\
\hline Minimally improved & - & $10(40.0)$ & 7 (28.0) & & & \\
\hline No change & - & $4(16.0)$ & $0(0.0)$ & & & \\
\hline Minimally worse & - & $0(0.0)$ & $0(0.0)$ & & & \\
\hline Much worse & - & $0(0.0)$ & $0(0.0)$ & & & \\
\hline Very much worse & - & $0(0.0)$ & $0(0.0)$ & & & \\
\hline Missing value & - & $1(4.0)$ & $2(8.0)$ & & & \\
\hline
\end{tabular}

${ }^{*} p<0.05,{ }^{\dagger} p<0.001$, ‡Friedman test with post-hoc Wilcoxon singed rank test revealed significant difference in mean rank reduction

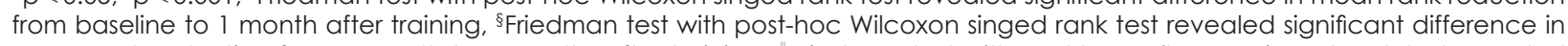
mean rank reduction from 1 month to 7 months after training, "Friedman test with post-hoc Wilcoxon singed rank test revealed significant difference in mean rank reduction from baseline to 7 months after training. ARS: Attention-Deficit Hyperactivity Disorder Rating Scale, CGI-I: Clinical Global Impression-Improvement, CGI-S: Clinical Global Impression-Severity, K-ARS: Korean version of ARS, SD: standard deviation 


\section{CWMT 훈련 전, 훈련 후 1 개월, 훈련 후 7 개월 시점의 ARS, $\mathrm{CGI}$ 평가}

$\mathrm{ADHD}$ 증상의 심각도, 전반적 기능, 전반적 문제행동에 관 한 CWMT의 결과를 비교하기 위하여 평균과 표준편차, 훈련 전, 훈련 후 1 개월, 훈련 후 7 개월, 세 시점의 차이에 대해 실시 된 Friedman test의 결과와, 이에 대한 사후 검증으로 실시된 Wilcoxon signed rank test의 결과를 Table 2에 제시하였다.

첫째, 임상가용 및 보호자용 $\mathrm{ARS}$ 에서 총점수의 세 시점 간 차이가 유의하였다 $\left(\chi^{2}=36.87, p<0.001 ; \chi^{2}=8.10, p=0.017\right)$. 사후 검정 결과, 임상가용 $\mathrm{ARS}$ 의 총점은 훈련 전-훈련 후 1 개월 ( $\mathrm{Z}=-4.05, \mathrm{p}<0.001)$, 훈련 후 1 개월-훈련 후 7개월 $(\mathrm{Z}=-3.48, \mathrm{p}<$ $0.001)$, 훈련 전-훈련 후 7 개월 $(\mathrm{Z}=-4.11, \mathrm{p}<0.001)$ 에서 모두
유의하게 감소하였고, 보호자용 $\mathrm{ARS}$ 의 총점은 훈련 전-훈련 후 1 개월 $(\mathrm{Z}=-2.15, \mathrm{p}=0.032)$, 훈련 전-훈련 후 7 개월 $(\mathrm{Z}=-2.736$, $\mathrm{p}=0.005$ )에서 유의하게 감소하였다. 또한, 임상가용 및 보호 자용 $\mathrm{ARS}$ 의 하위척도인 부주의성 점수에서 세 시점 간 차이 가 유의하였고 $\left.\chi^{2}=35.32, \mathrm{p}<0.001 ; \chi^{2}=7.37, \mathrm{p}=0.025\right)$, 과잉행동 성/충동성 점수에서 세 시점 간 차이가 유의하였다 $\left(\chi^{2}=27.11\right.$, $\left.\mathrm{p}<0.001 ; \chi^{2}=7.92, \mathrm{p}=0.019\right)$. 사후 검정 결과, 임상가용 ARS 의 부주의성 및 과잉행동성/충동성 점수와 보호자용 ARS의 부주의성 점수는 훈련 전-훈련 후 1 개월 $(\mathrm{Z}=-4.06, \mathrm{p}<0.001$; $\mathrm{Z}=-2.53, \mathrm{p}=0.001 ; \mathrm{Z}=-3.64, \mathrm{p}<0.001)$, 훈련 후 1 개월-훈련 후 7개월 $(\mathrm{Z}=-3.45, \mathrm{p}=0.001 ; \mathrm{Z}=-2.00, \mathrm{p}=0.045 ; \mathrm{Z}=-3.27, \mathrm{p}=0.001)$, 훈련 전-훈련 후 7 개월 $(Z=-4.11, p<0.001 ; Z=2.82, p=0.005$;

Table 3. Changes of the CAT from baseline to 1 month and 7 months after training $(n=23)$

\begin{tabular}{|c|c|c|c|c|c|c|}
\hline \multirow{2}{*}{ Variables } & \multirow{2}{*}{$\begin{array}{c}\text { Baseline } \\
\text { Mean } \pm S D\end{array}$} & \multirow{2}{*}{$\begin{array}{c}\text { Month } 1 \\
\text { Mean } \pm S D\end{array}$} & \multirow{2}{*}{$\begin{array}{c}\text { Month } 7 \\
\text { Mean } \pm S D\end{array}$} & \multirow{2}{*}{ df } & \multirow{2}{*}{$\chi^{2}$ or $Z$} & \multirow{2}{*}{$\mathrm{p}$} \\
\hline & & & & & & \\
\hline \multicolumn{7}{|l|}{ Visual selective attention test } \\
\hline Omission error & $0.39 \pm 1.03$ & $0.17 \pm 0.49$ & $5.74 \pm 17.29$ & 2 & 1.61 & 0.446 \\
\hline Commission error & $1.78 \pm 2.44$ & $1.22 \pm 1.99$ & $0.43 \pm 0.78$ & 2 & 7.90 & $0.019^{*}$ \\
\hline Response time & $396.93 \pm 76.85$ & $413.65 \pm 74.11$ & $424.78 \pm 102.81$ & 2 & 1.07 & 0.584 \\
\hline Response time SD & $67.34 \pm 29.43$ & $86.78 \pm 48.21$ & $63.77 \pm 27.73$ & 2 & 4.81 & 0.090 \\
\hline \multicolumn{7}{|l|}{ Auditory selective attention test } \\
\hline Omission error & $0.48 \pm 1.08$ & $0.70 \pm 1.66$ & $0.87 \pm 2.51$ & 2 & 0.46 & 0.792 \\
\hline Commission error ${ }^{\S, \|}$ & $2.48 \pm 2.39$ & $2.00 \pm 2.25$ & $1.04 \pm 1.74$ & 2 & 16.0 & $0.000^{\dagger}$ \\
\hline Response time & $563 \pm 124.43$ & $578.49 \pm 131.8$ & $580.11 \pm 180.68$ & 2 & 0.28 & 0.867 \\
\hline Response time SD & $141.17 \pm 77.14$ & $143.48 \pm 56.7$ & $118.85 \pm 70.75$ & 2 & 5.03 & 0.081 \\
\hline \multicolumn{7}{|c|}{ Sustained attention test to response task } \\
\hline Omission error & $2.91 \pm 5.36$ & $2.91 \pm 4.36$ & $5.13 \pm 13.77$ & 2 & 0.41 & 0.814 \\
\hline Commission error ${ }^{\S}$ & $8.22 \pm 9.38$ & $7.48 \pm 7.08$ & $5.74 \pm 6.18$ & 2 & 7.97 & $0.019^{*}$ \\
\hline Response time & $479.63 \pm 101.8$ & $457.52 \pm 94.04$ & $473.59 \pm 97.38$ & 2 & 1.47 & 0.479 \\
\hline Response time SD & $116.61 \pm 46.94$ & $112.08 \pm 44.9$ & $100.49 \pm 36.34$ & 2 & 4.62 & 0.099 \\
\hline \multicolumn{7}{|l|}{ Flanker test } \\
\hline Omission error & $1.0 \pm 1.5$ & $1.43 \pm 3.57$ & $1.87 \pm 3.44$ & 2 & 0.52 & 0.770 \\
\hline Commission error ${ }^{\S, \|}$ & $6.48 \pm 7.52$ & $5.74 \pm 6.24$ & $3.57 \pm 3.57$ & 2 & 8.02 & $0.018^{*}$ \\
\hline Response time & $488.77 \pm 95.01$ & $478.4 \pm 84.52$ & $493.42 \pm 93.11$ & 2 & 1.07 & 0.584 \\
\hline Response time SD & $101.88 \pm 49.38$ & $93.1 \pm 41.58$ & $91.27 \pm 46.49$ & 2 & 0.66 & 0.968 \\
\hline \multicolumn{7}{|l|}{ Divided attention test } \\
\hline Omission error & $7.86 \pm 7.76$ & $5.82 \pm 6.89$ & $6.14 \pm 6.44$ & 2 & 1.30 & 0.522 \\
\hline Commission error & $7.36 \pm 9.85$ & $4.55 \pm 3.62$ & $4.27 \pm 3.90$ & 2 & 4.48 & 0.106 \\
\hline Response time & $720.51 \pm 160.47$ & $673.25 \pm 162.22$ & $701.19 \pm 128.53$ & 2 & 2.19 & 0.334 \\
\hline Response time $\mathrm{SD}^{\ddagger}$ & $252.97 \pm 80.91$ & $199.87 \pm 52.99$ & $254.25 \pm 200.19$ & 2 & 7.10 & $0.029 *$ \\
\hline \multicolumn{7}{|l|}{ Spatial working memory } \\
\hline Forward correct response & $7.59 \pm 2.77$ & $10.59 \pm 3.24$ & $10.55 \pm 2.42$ & 2 & 25.27 & $0.000^{\dagger}$ \\
\hline Forward memory span ${ }^{\ddagger . l l}$ & $5.68 \pm 1.52$ & $6.95 \pm 1.73$ & $7.09 \pm 1.73$ & 2 & 17.64 & $0.000^{\dagger}$ \\
\hline Backward correct response ${ }^{\ddagger, \|}$ & $8.27 \pm 2.33$ & $10.00 \pm 2.81$ & $9.59 \pm 2.28$ & 2 & 17.62 & $0.000^{\dagger}$ \\
\hline Backward memory span ${ }^{\ddagger . \|}$ & $5.95 \pm 1.17$ & $6.77 \pm 1.60$ & $6.77 \pm 1.71$ & 2 & 17.28 & $0.000^{\dagger}$ \\
\hline
\end{tabular}

${ }^{*} \mathrm{p}<0.05,{ }^{\dagger} \mathrm{p}<0.001$, fFriedman test with post-hoc Wilcoxon singed rank test revealed significant difference in mean rank reduction from baseline to 1 month after training, §Friedman test with post-hoc Wilcoxon singed rank test revealed significant difference in mean rank reduction from 1 month to 7 months after training, "Friedman test with post-hoc Wilcoxon singed rank test revealed significant difference in mean rank reduction from baseline to 7 months after training. CAT: Comprehensive Attention Test, SD: standard deviation 
$\mathrm{Z}=-2.39, \mathrm{p}=0.017)$ 에서 모두 유의한 감소를 보였고, 보호자용 $\mathrm{ARS}$ 의 과잉행동성/충동성 점수는 훈련 전-훈련 후 7개월 $(\mathrm{Z}=-2.74, \mathrm{p}=0.006)$ 에 유의하게 감소하였다.

둘째, CGI-S의 점수에서 세 시점 간 유의한 차이가 있었고 $\left(\chi^{2}=27.11, p<0.001\right)$, 사후 검정 결과 훈련 전-훈련 후 1 개월 $(\mathrm{Z}=-3.42, \mathrm{p}=0.001)$, 훈련 후 1 개월-훈련 후 7 개월 $(\mathrm{Z}=-2.97$, $\mathrm{p}=0.003)$, 훈련 전-훈련 후 7 개월 $(\mathrm{Z}=-3.59, \mathrm{p}<0.001)$ 에서 모 두 감소가 유의하였다. CGI-I 평가 결과 훈련 후 1 개월 시점의 반응군은 $40 \%$, 부분반응군은 $40 \%$ 였고, 훈련 후 7개월 시점 의 반응군은 $60 \%$, 부분반응군은 $28 \%$ 였다.

\section{CWMT 훈련 전, 훈련 후 1개월, 훈련 후 7개월 시점의 CAT 결과}

훈련 전, 훈련 후 1 개월, 훈련 후 7 개월 시점의 CAT 6 개 하위 검사에서 산출된 측정치를 비교하였다(Table 3).

$\mathrm{CAT}$ 중 선택적 단순주의력(시각), 선택적 단순주의력(청각), 억제지속주의력, 간섭선택주의력 하위검사에서 오경보 오류 (commission error) 항목의 세 시점 간 차이가 유의미하였다 $\left(\chi^{2}=7.90, \mathrm{p}<0.019 ; \chi^{2}=16.0, \mathrm{p}<0.000 ; \chi^{2}=7.97, \mathrm{p}<0.019 ; \chi^{2}=\right.$ $8.02, \mathrm{p}<0.018)$. 사후 검정 결과, 선택적 단순주의력(시각), 선 택적 단순주의력(청각), 간섭선택주의력의 오경보 오류가 훈 련 후 1 개월-훈련 후 7개월( $\mathrm{Z}=-2.166, \mathrm{p}<0.030 ; \mathrm{Z}=-3.402, \mathrm{p}<$ $0.001 ; Z=-2.425, p<0.015)$, 훈련 전-훈련 후 7개월 $(Z=-2.885$, $\mathrm{p}<0.004 ; \mathrm{Z}=-3.179, \mathrm{p}<0.001 ; \mathrm{Z}=-2.160, \mathrm{p}<0.031)$ 에서 유의 하게 감소하였고, 억제지속주의력의 오경보 오류가 훈련 후 1 개월-훈련 후 7 개월 $(\mathrm{Z}=-2.244, \mathrm{p}<0.025)$ 에서 유의한 감소를 보였다. 또한 분할 주의력검사의 반응시간 표준편차 항목에서 시점 간 차이가 유의미하였다 $\left(\chi^{2}=7.10, p<0.029\right)$. 사후 검정 결 과, 반응시간 표준편차가 훈련 전-훈련 후 1 개월 $(\mathrm{Z}=-3.001, \mathrm{p}<$ 0.003)에서 유의미하게 감소하였고, 훈련 후 7개월까지는 유지 되지 못하였다. 한편 작업기억력 순방향과 역방향 과제 모두 정반응 횟수와 공간폭에서 세 시점 간 유의한 차이가 나타났다 $\left(\chi^{2}=25.27, \mathrm{p}<0.000 ; \chi^{2}=17.64, \mathrm{p}<0.000 ; \chi^{2}=17.62, \mathrm{p}<0.000 ; \chi^{2}=\right.$ $17.28, \mathrm{p}<0.000)$. 사후 검정 결과, 순방향 과제의 정반응 횟수 와 공간폭이 훈련 전-훈련 후 1 개월 $(\mathrm{Z}=-3.858, \mathrm{p}<0.000$; $\mathrm{Z}=$ $-3.423, p<0.001)$, 훈련 전-훈련 후 7 개월 $(Z=-3.736, p<0.000$; $\mathrm{Z}=-3.255, \mathrm{p}<0.001)$ 에서 유의하게 증가하였다. 역방향 과제에 서도 정반응 횟수와 공간폭이 훈련 전-훈련 후 1 개월(Z=-3.092, $\mathrm{p}<0.002 ; \mathrm{Z}=-2.916, \mathrm{p}<0.004)$, 훈련 전-훈련 후 7개월 $(\mathrm{Z}=-2.474$, $\mathrm{p}<0.013 ; \mathrm{Z}=-2.610, \mathrm{p}<0.009)$ 에서 유의하게 증가를 보였다.

\section{고 찰}

본 연구는 약물치료에 부분적인 반응을 보이는 $\mathrm{ADHD}$ 아
동 및 청소년을 대상으로 CWMT를 실시하여 임상증상 및 신 경인지기능의 부가적인 효과를 확인하고자 하였다. 그 결과 보호자와 임상가가 평가한 임상증상 및 기능이 호전되었다. 또 한 선택적 단순주의력(시각/청각), 억제지속주의력, 간섭선택 주의력 과제에서 오경보 오류가 유의하게 감소하였으며, 분할 주의력 과제에서 반응시간 표준편차가 감소하였고, 작업기억 력 과제에서 공간폭뿐만 아니라 수행의 정확도가 증가됨이 관찰되었다. 또한 이 효과는 상당 부분 훈련 후 7개월까지 지 속되었다.

전 세계적으로 $\mathrm{ADHD}$ 환자의 증상 및 기능 개선을 위해서 는 가장 먼저 약물치료가 권고된다. 하지만 장기적 치료 효과 와 부작용에 의한 제한점으로 인해, 임상상황에서는 약물치 료 하나만으로 효과가 충분하지 못한 경우를 종종 경험한 다. ${ }^{60)}$ 그러한 경우, 임상가들은 자연스럽게 어떤 비약물적인 치 료를 부가적으로 적용할 수 있을지 고민하게 되는데, 본 연구 결과 CWMT를 또다른 치료적 대안 중 하나로 시도해 볼 수 있겠다.

특히, 임상가 평정 $\mathrm{ARS}$ 의 총점, 부주의성 점수, 과잉행동/충 동성 점수와 보호자 평정 ARS의 부주의성 점수가 훈련 전훈련 후 1 개월, 훈련 후 1 개월-훈련 후 7개월의 두 기간에서 유 의하게 감소하였고, 보호자 평정 $\mathrm{ARS}$ 의 총점이 훈련 전-훈 련 후 1 개월, 훈련 전-훈련 후 7 개월의 두 기간에서 유의하게 감소하였으며, 보호자 평정 $\mathrm{ARS}$ 의 과잉행동/충동성 점수는 훈 련 전-훈련 후 7개월에서 유의하게 감소하였다. 이는 Klingberg 등 ${ }^{47)}$ 과 Beck 등 ${ }^{61}$ 이 보고한 부모평정 부주의성 및 과잉행동/ 충동성의 감소, van Dongen-Boomsma 등 ${ }^{62}$ 과 Bigorra 등 ${ }^{63)}$ 이 보고한 $\mathrm{ADHD}$ 증상의 감소와 일치하는 결과이다. 또한 van Dongen-Boomsma 등 ${ }^{64}$ 이 작업기억력 과제에서의 수행 향상 도가 교사 평정 $\mathrm{ADHD}$ 증상의 감소도와 유의한 상관관계가 있다는 연구 결과와도 일치하는 소견이다. 결국 주의력과 행동 을 조절하는 작업기억력의 본래 기능이 회복되면서, $\mathrm{ADHD}$ 의 핵심증상이 감소되는 것으로 판단된다. ${ }^{65)}$ 또한 전반적인 기능 수준을 평가한 임상가 평정 CGI-S의 점수가 훈련 전훈련 후 1 개월, 훈련 후 1 개월-훈련 후 7 개월의 두 기간에서 유의하게 감소하였고, 임상가 평정 CGI-I 결과 훈련 후 1개월 에 $80 \%$, 훈련 후 7개월에서 $88 \%$ 가 효과를 보았다. 특히 훈련 후 1 개월에는 $40 \%$, 훈련 후 7 개월 시점에서는 $60 \%$ 에서 상당 한 수준의 기능 호전이 관찰되었다. 이는 작업기억력 훈련 이후 에 전반적인 기능의 향상라 혹은 기능 손상의 감소 ${ }^{63,66)}$ 를 보고 한 과거 연구 결과와 일치한다. 또한 훈련 직후보다는 시간이 지남에 따라 기능이 점점 더 호전되는 지연효과를 보였는데, 이는 작업기억력의 증가가 생활능력의 향상으로 이어지기까 지 다소 시간이 필요함을 시사하며 훈련 후 수학학습능력이 
6개월 이후에 호전되었다는 기존 연구 결과와도 일치하는 소 견이다. ${ }^{67)}$

신경인지기능을 평가한 CAT의 선택적 단순주의력(시각, 청 각), 간섭선택주의력 과제에서 오경보 오류가 훈련 전-훈련 후 7개월, 훈련 후 1 개월-훈련 후 7개월에서 유의하게 감소하 였고, 억제지속주의력 과제에서는 오경오 오류가 훈련 후 1 개 월-훈련 후 7 개월에서 유의하게 감소되었다. 또한 분할 주의 력에서의 반응시간 표준편차가 훈련 전-훈련 후 1 개월에서 유의하게 감소하였고, 작업기억력 검사의 순방향과 역방향 과 제 모두에서 정반응 횟수와 공간폭이 훈련 전-훈련 후 1 개월, 훈련 전-훈련 후 7개월에서 유의하게 증가하였다. 이는 목표 자극에 대한 선택적 주의력과 작업기억력의 용량이 향상됨을 의미하며, 집중적인 작업기억력 훈련을 통해 작업기억력과 지 속주의력, 반응 억제력 등이 향상되었다는 Klingberg 등 ${ }^{47,68)}$ 과 Kerns 등, ${ }^{69)}$ Egeland 등 ${ }^{52)}$ 의 연구 결과와 일치한다. 본 연 구에서는 선택적 단순주의력(시각, 청각), 억제지속주의력, 간 섭선택주의력 과제에서 일관되게 오경보 오류가 감소됨이 확 인되었는데, 작업기억력이나 주의력을 향상시킬 뿐만 아니라 충동성을 통제하는 반응 억제력에도 긍정적인 영향이 나타난 것으로 생각된다. 작업기억력 훈련을 통해 목표 자극에 충동 적이지 않고 정확하게 반응하는 패턴을 내재화하게 되는 것 으로 보이며, 이는 전두엽 부위에서 중개된다고 알려진 실행 기능이 호전되면서 반응 억제력이 향상된 것으로 사료된다. 이 전 연구들 ${ }^{47,61)}$ 에서는 작업기억력 훈련 후 주로 부모의 보고를 통해 충동성의 감소가 확인된 것에 반해 본 연구에서는 객관 적인 검사를 통해 충동성의 감소와 반응 억제력의 향상이 확 인되었다는 점에서 의미가 있겠다.

이러한 결과를 종합할 때, CWMT는 약물치료를 받고 있 는 $\mathrm{ADHD}$ 아동 및 청소년의 임상증상과 전반적 기능을 개선 시키고, 주의력과 작업기억력, 반응 억제력을 향상시킬 수 있 는 유용한 프로그램이라는 것을 알 수 있다. 본 연구의 제한점 으로는 연구대상자의 수가 적고, 단일 센터에 내원하는 아동 만을 대상으로 했다는 점, 통제 집단이 없었다는 점 등이 있겠 으며, 후속 연구에서는 이러한 제한점을 보완한 연구가 필요할 것으로 보인다.

\section{결 론}

본 연구 결과, CWMT를 통해 약물치료에 부분적 반응을 보 이는 $\mathrm{ADHD}$ 아동 및 청소년의 주의력과 작업기억력, 반응 억 제력을 호전시킬 수 있었고, $\mathrm{ADHD}$ 의 핵심증상과 임상적 기능 에 긍정적인 효과가 나타났으며, 대부분의 효과는 훈련 후 7 개월까지 유지되었다.
중심 단어:작업기억력 훈련; 코그메드;

주의력결핍 과잉행동장애; 신경심리.

\section{Conflicts of Interest}

The authors have no financial conflicts of interest.

\section{REFERENCES}

1) Dulcan M. Practice parameters for the assessment and treatment of children, adolescents, and adults with attention-deficit/hyperactivity disorder. American Academy of Child and Adolescent Psychiatry. J Am Acad Child Adolesc Psychiatry 1997;36(10 Suppl):85S121S.

2) Barkley RA. ADHD in adults: developmental course and outcome of children with ADHD, and ADHD in clinic-referred adults. In: Barkley RA, editor. Attention-deficit hyperactivity disorder: a handbook for diagnosis and treatment. 3rd ed. New York: Guilford Press; 2006. p.248-296.

3) Nigg JT. Neuropsychologic theory and findings in attention-deficit/hyperactivity disorder: the state of the field and salient challenges for the coming decade. Biol Psychiatry 2005;57:1424-1435.

4) Seidman LJ. Neuropsychological functioning in people with ADHD across the lifespan. Clin Psychol Rev 2006;26:466-485.

5) Nigg JT, Stavro G, Ettenhofer M, Hambrick DZ, Miller T, Henderson JM. Executive functions and ADHD in adults: evidence for selective effects on ADHD symptom domains. J Abnorm Psychol 2005;114:706-717.

6) Barkley RA. Major life activity and health outcomes associated with attention-deficit/hyperactivity disorder. J Clin Psychiatry 2002;63 Suppl 12:10-15.

7) Barkley RA. Attention-deficit hyperactivity disorder: a handbook for diagnosis and treatment. New York: Guilford Press;1990.

8) Doyle AE. Executive functions in attention-deficit/hyperactivity disorder. J Clin Psychiatry 2006;67 Suppl 8:21-26.

9) Barkley RA, Grodzinsky G, DuPaul GJ. Frontal lobe functions in attention deficit disorder with and without hyperactivity: a review and research report. J Abnorm Child Psychol 1992;20:163-188.

10) Goodyear P, Hynd GW. Attention-deficit disorder with (ADD/H) and without (ADD/WO) hyperactivity: behavioral and neuropsychological differentiation. J Clin Child Psychol 1992;21:273-305.

11) Barkley RA. Behavioral inhibition, sustained attention, and executive functions: constructing a unifying theory of ADHD. Psychol Bull 1997;121:65-94.

12) Kuntsi J, Oosterlaan J, Stevenson J. Psychological mechanisms in hyperactivity: I. Response inhibition deficit, working memory impairment, delay aversion, or something else? J Child Psychol Psychiatry 2001;42:199-210.

13) Rapport MD, Chung KM, Shore G, Denney CB, Isaacs P. Upgrading the science and technology of assessment and diagnosis: laboratory and clinic-based assessment of children with ADHD. J Clin Child Psychol 2000;29:555-568.

14) Barkley RA. Attention-deficit/hyperactivity disorder. In: Mash EJ, Barkley RA, editors. Child psychopathology. 2nd ed. New York: Guilford Press;2003. p.75-143.

15) Shin MS, Kim HM, On SG, Hwang JW, Kim BN, Cho SC. Comparison of executive function in children with ADHD, Asperger's disorder, and learning disorder. J Korean Acad Child Adolesc Psychiatry 2006;17:131-140.

16) Denckla MB. Measurement of executive function. In: Lyon GR, editor. Frames of reference for the assessment of learning disabilities. New views on measurement issues. Baltimore: Brookers;1994. p.117142.

17) Smith EE, Jonides J. Storage and executive processes in the frontal lobes. Science 1999;283:1657-1661.

18) Baddeley A. Working memory, thought and action. New York: 
Oxford University Press;2007.

19) Kofler MJ, Rapport MD, Bolden J, Altro TA. Working memory as a core deficit in ADHD: preliminary findings and implications. ADHD Rep 2008;16:8-14.

20) Kim JH, Hong SD. Executive functions of attention deficit/ hyperactivity disorder. J Korean Acad Child Adolesc Psychiatry 1999;10: $15-20$.

21) Park S, Kim JY, Choi SH, Yoo HK, Hong JP, Kim SY, et al. A preliminary study of the efficacy and safety of bupropion as the second-line drug in children with attention deficit hyperactivity disorder. Korean J Psychopharmacol 2006;17:461-467.

22) Shin JY, Yang JW, Jang WS, Hong SD. Prescription status and efficacy of OROS-MPH and parent perception in children with attention deficit hyperactivity disorder: multi-center, observational study during 4 weeks. Korean J Psychopharmacol 2007;18:50-59.

23) Barkley RA. Attention-deficit hyperactivity disorder: a handbook for diagnosis and treatment. 2nd ed. New York: Guilford Press;1998.

24) Pietrzak RH, Mollica CM, Maruff P, Snyder PJ. Cognitive effects of immediate-release methylphenidate in children with attentiondeficit/hyperactivity disorder. Neurosci Biobehav Rev 2006;30:12251245.

25) Riccio CA, Waldrop JJ, Reynolds CR, Lowe P. Effects of stimulants on the continuous performance test (CPT): implications for CPT use and interpretation. J Neuropsychiatry Clin Neurosci 2001;13: 326-335.

26) Yoo HK, Kim B, Joung YS, Bahn GH, Song DH, Ahn DH, et al. An open-label study of the improvements in clinical symptoms and neurocognitive functions in Korean children and adolescents with attention deficit hyperactivity disorder after treatment with metadate CD. J Korean Acad Child Adolesc Psychiatry 2011;22:253-261.

27) Pelham WE. Pharmacotherapy for children with attention-deficit hyperactivity disorder. School Psychol Rev 1993;22:199-227.

28) Banaschewski T, Coghill D, Santosh P, Zuddas A, Asherson P, Buitelaar J, et al. Long-acting medications for the hyperkinetic disorders. A systematic review and European treatment guideline. Eur Child Adolesc Psychiatry 2006;15:476-495.

29) Kim HL, Kim JW, Hong SB, Cho JH, Kim BN, Shin MS, et al. Effects of neurofeedback in children with attention deficit hyperactivity disorder: a preliminary study. J Korean Neuropsychiatr Assoc 2012;51:326-334.

30) A 14-month randomized clinical trial of treatment strategies for attention-deficit/hyperactivity disorder. The MTA Cooperative Group. Multimodal treatment study of children with ADHD. Arch Gen Psychiatry 1999;56:1073-1086.

31) Jensen PS, Arnold LE, Swanson JM, Vitiello B, Abikoff HB, Greenhill LL, et al. 3-year follow-up of the NIMH MTA study. J Am Acad Child Adolesc Psychiatry 2007;46:989-1002.

32) Molina BS, Hinshaw SP, Swanson JM, Arnold LE, Vitiello B, Jensen PS, et al. The MTA at 8 years: prospective follow-up of children treated for combined-type ADHD in a multisite study. J Am Acad Child Adolesc Psychiatry 2009;48:484-500.

33) Schachar R, Herzog W, Leonard TR. Force enhancement above the initial isometric force on the descending limb of the force-length relationship. J Biomech 2002;35:1299-1306.

34) August GJ, Realmuto GM. Pharmacotherapy in ADHD. Guidelines for prescribing stimulant medications in young children. Minn Med 2000;83:45-46.

35) Prince JB. Pharmacotherapy of attention-deficit hyperactivity disorder in children and adolescents: update on new stimulant preparations, atomoxetine, and novel treatments. Child Adolesc Psychiatr Clin N Am 2006;15:13-50.

36) Kim IH. Effect of the group art therapy in children with attentiondeficit hyperactivity disorder(ADHD). J Korean Acad Psychiatr Mental Health Nurs 2006;15:152-160.

37) Lee DH, Kim MS, Song YJ, Kwon BM. An exploratory review of literature on peer relationship of children with ADHD. Korean J Couns Psychother 2013;25:643-672.

38) Park SH, Go H. A case study applying both cognitive behavioral therapy and art psychotherapy to an ADHD child. J Arts Psychother 2010;6:79-99.

39) Abikoff H. An evaluation of cognitive behavior therapy for hyperactive children. Adv Clin Child Psychol 1987;10:171-216.

40) Bugental DB, Collins S, Collins L, Chaney LA. Attributional and behavioral changes following two behavior management interventions with hyperactive boys: a follow-up study. Child Dev 1978;49: 247-250.

41) Gevensleben H, Holl B, Albrecht B, Vogel C, Schlamp D, Kratz O, et al. Is neurofeedback an efficacious treatment for ADHD? A randomised controlled clinical trial. J Child Psychol Psychiatry 2009; 50:780-789.

42) Holtmann M, Sonuga-Barke E, Cortese S, Brandeis D. Neurofeedback for ADHD: a review of current evidence. Child Adolesc Psychiatr Clin N Am 2014;23:789-806.

43) Baydala L, Wikman E. The efficacy of neurofeedback in the management of children with attention deficit/hyperactivity disorder. Paediatr Child Health 2001;6:451-455.

44) Løhaugen GC, Antonsen I, Håberg A, Gramstad A, Vik T, Brubakk AM, et al. Computerized working memory training improves function in adolescents born at extremely low birth weight. J Pediatr 2011;158:555-561.e4.

45) Thorell LB, Lindqvist S, Bergman Nutley S, Bohlin G, Klingberg T. Training and transfer effects of executive functions in preschool children. Dev Sci 2009;12:106-113.

46) Klingberg T. Training and plasticity of working memory. Trends Cogn Sci 2010;14:317-324.

47) Klingberg T, Fernell E, Olesen PJ, Johnson M, Gustafsson P, Dahlstrom K, et al. Computerized training of working memory in children with ADHD-a randomized, controlled trial. J Am Acad Child Adolesc Psychiatry 2005;44:177-186.

48) Holmes J, Gathercole SE. Taking working memory training from the laboratory into schools. Educ Psychol (Lond) 2014;34:440-450.

49) Bergman-Nutley S, Klingberg T. Effect of working memory training on working memory, arithmetic and following instructions. Psychol Res 2014;78:869-877.

50) Green CT, Long DL, Green D, Iosif AM, Dixon JF, Miller MR, et al. Will working memory training generalize to improve off-task behavior in children with attention-deficit/hyperactivity disorder? Neurotherapeutics 2012;9:639-648.

51) Fälth $L$, Jaensson $L$, Johansson $K$. Working memory training-a cogmed intervention. Int J Learn Teach Educ Res 2015;14:28-35.

52) Egeland J, Aarlien AK, Saunes BK. Few effects of far transfer of working memory training in ADHD: a randomized controlled trial. PLoS One 2013;8:e75660.

53) Dunning DL, Holmes J, Gathercole SE. Does working memory training lead to generalized improvements in children with low working memory? A randomized controlled trial. Dev Sci 2013;16: 915-925.

54) Olesen PJ, Westerberg H, Klingberg T. Increased prefrontal and parietal activity after training of working memory. Nat Neurosci 2004; 7:75-79.

55) Korean Educational Development Institute. KEDI-WISC test manual. Seoul: Korean Educational Development Institute;1991.

56) DuPaul GJ. Parent and teacher ratings of ADHD symptoms: psychometric properties in a community-based sample. J Clin Child Adoles Psychol 1991;20:245-253.

57) So YK, Noh JS, Kim YS, Ko SG, Koh YJ. The reliability and validity of Korean parent and teacher ADHD rating scale. J Korean Neuropsychiatr Assoc 2002;41:283-289.

58) Haro JM, Kamath SA, Ochoa S, Novick D, Rele K, Fargas A, et al. The Clinical Global Impression-Schizophrenia Scale: a simple in- 
strument to measure the diversity of symptoms present in schizophrenia. Acta Psychiatr Scand Suppl 2003;107:16-23.

59) Lee JS, Kang SH, Park EH, Jung JS, Kim BN, Son JW, et al. Standardization of the comprehensive attention test for the Korean children and adolescents. J Korean Acad Child Adoles Psychiatry 2009; 20:68-75.

60) Bikic A, Leckman JF, Lindschou J, Christensen TØ, Dalsgaard S. Cognitive computer training in children with attention deficit hyperactivity disorder (ADHD) versus no intervention: study protocol for a randomized controlled trial. Trials 2015;16:480.

61) Beck SJ, Hanson CA, Puffenberger SS, Benninger KL, Benninger WB. A controlled trial of working memory training for children and adolescents with ADHD. J Clin Child Adolesc Psychol 2010;39:825836.

62) van Dongen-Boomsma M, Vollebregt MA, Slaats-Willemse D, Buitelaar JK. [Efficacy of frequency-neurofeedback and Cogmed JMworking memory training in children with ADHD]. Tijdschr Psychiatr 2015;57:508-516.

63) Bigorra A, Garolera M, Guijarro S, Hervás A. Long-term far-transfer effects of working memory training in children with ADHD: a randomized controlled trial. Eur Child Adolesc Psychiatry 2016;25: 853-867.

64) van Dongen-Boomsma M, Vollebregt MA, Buitelaar JK, SlaatsWillemse D. Working memory training in young children with ADHD: a randomized placebo-controlled trial. J Child Psychol Psychiatry 2014;55:886-896.

65) Hasher L, Zacks RT. Working memory, comprehension, and aging: a review and a new view. Psychol Learn Motiv 1988;22:193-225.

66) Stevens MC, Gaynor A, Bessette KL, Pearlson GD. A preliminary study of the effects of working memory training on brain function. Brain Imaging Behav 2016;10:387-407.

67) Holmes J, Gathercole SE, Dunning DL. Adaptive training leads to sustained enhancement of poor working memory in children. Dev Sci 2009;12:F9-F15.

68) Klingberg $\mathrm{T}$, Forssberg $\mathrm{H}$, Westerberg $\mathrm{H}$. Training of working memory in children with ADHD. J Clin Exp Neuropsychol 2002;24:781791.

69) Kerns KA, Eso K, Thomson J. Investigation of a direct intervention for improving attention in young children with ADHD. Dev Neuropsychol 1999;16:273-295. 